appointed to report upon possible ways and means of furthering the claims of school science, and of raising it from its present position, in view of the fact that the status of science in the public schools has so important a relation to the recognition of science by the nation's leaders.

The Association of Teachers in Technical Institutions arranged a discussion on "Technical Education: the War and After," which formed part of the great conference at the University of London. The attendance was relatively small; a fact quite creditable to the Association, as the absentees were all engaged on technical work of value and urgency in connection with the war. Nevertheless the quality of the papers and speeches evoked justified the organisers of the meeting-they will be read both in England and abroad in the general report of the Conference. Mr. Barker North (Bradford Technical College) reviewed the situation, laying emphasis on the necessity for maintaining the efficiency of technical institutions if we wish to succeed in the coming industrial war. $\mathrm{He}$ advocated more central organisation, not only in in struction and research, but also in commerce and industry. Referring to the Board of Education, he reiterated Mr. Abbott's warning that any diminution in expenditure which interferes with the efficiency of technical education will handicap the nation in the coming industrial struggle.

Mr. James Baker vividly sketched the contrast between England, with miserably limited technical departments and slum-infected cities, and Bohemia, with splendid scientific institutions, rapidly advancing industries, and consequenc abolition of poverty. Incidentally he referred to the high state of general culture and enlightenment in Bohemia, where the people wish to be on England's side in the war.

Dr. C. Dorée considered the possibilities of indus trial research work in technical institutions. The remarkable applications of science in the war have opened the eyes of manufacturers, and many firms for the first time have employed a chemist. What is more, they have admitted that scientific methods pay better, and that Government specifications are passed more easily with a chemist than without one. Those firms are not likely to do without such trained assistance in the future. Seeing that instruction must form a large part of the work of technical institutions, it is recommended that a director of research should find out problems, obtain material, and apportion the work among the institutes according to their capacity. Such centrally directed work is now being carried out in making drugs, and is quite successful.

The Science Teachers' Association also held a successful meeting, the description of which must be deferred. Efforts to broaden the membership and widen the work of this society are being considered. The Council of the Association will do well to throw its energies at once into the work of expansion.

The striking vigour and success of the whole Conference of Associations demonstrate that teachers are alive to the national position. Their united efforts are needed to make clear to the public, and to persons in high authority, that upon education, and especially on scientific education, depends our progress towards a wiser England.

G. F. Daniell.

\section{PRIZE AWARDS OF THE PARIS ACADEMY OF SCIENCES, 1915.}

Mathematics.-The Francœur prize is awarded to Joseph Marty for his work on the theory of integral equations. The Bordin prize is postponed to I9I6.

Mechanics.-No award was made of the Montyon prize; the Poncelet prize is accorded to Charles Rabut, for his work as a whole; Umberto Puppini receives the Boileau prize, for his work in hydraulics.

Astronomy.-The Lalande prize to Lucien d'Azambuja, for his important contribution to the daily measurement of the upper layer of the solar atmosphere and to the recognition of the action exercised by the magnetic field on band spectra; the Valz prize to Armand Lambert, for his work as an observer and in applied mathematics; the G. de Pontécoulant prize to Louis Fabry, for his researches on the asteroids; no award of the Pierre Guzman prize is made.

Geography.-The Tchihatchef prize to J. CouyatBarthoux, for his geological and geographical work on the Sinai and Suez Canal regions; the Gay prize to Henri Lecomte, for his studies on the distribution of plants in Indo-China.

Navigation.-The Extraordinary prize of 6000 francs is divided between Maurice Marchand (300o francs), for his memoir on the protection of the submarine against mines, Jean Lorfèvre (I 500 francs), for his essay on the use of Diesel motors, and Louis Jauch and Auguste Masméjean (I500 francs jointly), for their work on marine engines; the Plumey prize is not awarded.

Physics.-The Hebert prize to Michael Idvorsky Pupin, for the whole of his work in applied electricity; the Hughes prize to $R$. Marcelin, for his theoretical and experimental memoir entitled "Contribution to the Study of Physico-Chemical Kinetics"; the H. de Parville prize to Jean Blein, for his contributions to the thermodynamics of gases and detectors in wireless telegraphy; the Gaston Planté prize to Marcel Moulin, for his researches on the positive rays of radium, ionisation, radiation of black bodies, and other interesting questions of modern physics; the Pierson-Perrin prize to Maurice de Broglie, for his studies on ionised gases, the Brownian movement, and the diffraction of the $\mathrm{X}$-rays.

Chemistry. - The Jecker prize to Gabriel Bertrand, for his work in organic and biological chemistry; the Cahours prize to Paul Viguier, for his researches on tetrolic aldehyde and some of its derivatives; the Montyon prize (unhealthy trades) to André Kling (2500 francs), for his work in the Paris Municipal Laboratory; honourable mentions (1500 francs), to Daniel Florentin and René Schmutz (Iooo francs); the Houzeau prize to Paul Pascal, for the whole of his work in inorganic and organic chemistry.

Mineralogy and Geology.-The Delesse prize to Albert de Romeu, for his petrographic researches, and an encouragement (1000 francs) to A. Laville. for his researches on fossil vertebrates; the Joseph Labbé prize to René Tronquoy, for his studies on tin ore deposits; the Victor Raulin prize to Louis Doncieux, for his palæontological researches; no award of the Cuvier prize is made, and the funds will be used for charitable purposes.

Botany.-The Desmazières prize to Giovanni Battista de Toni and Achille Forti, for their contributions to the Mediterranean algological flora; the Montagne prize to Fernand Camus; the de Coincy prize to Pierre Choux, for the whole of his botanical work; the Thore prize to Isidore Doin; the de Rufz de Lavison prize to Paul Becquerel, for his researches on the life of seeds.

Anatomy and Zoology.-The Savigny prize to Pierre Fauvel, for his researches on annelids obtained in the voyages of the Hirondelle and the Princess Alice; the da Gama Machado prize is not awarded.

Medicine and Surgery.-Montyon prizes: A prize of 2500 francs to Francois Maignon, for his researches on the toxicity of albumenoid materials; an honourable mention of $\mathrm{I}_{5} 00$ francs to Emile Terroine, for his work on pancreatic secretion; citations to Eugène Olivier and Dr. Ginestoux: the Barbier prize to Charles Dassonville and Cléry Rivière, for their memoir on epizootic abortion in mares: very honourable mentions to Charles Besnoit and V. Robin, for their works on cutaneous sarcosporidiosis of the ox, 
and to Henri Bocquillon, for his botanical and therapeutical studies of tropical plants; 2500 francs from the interest on the Breant prize to $\mathrm{M}$. Brumpt, for his work on parasitology; the Godard prize to Noël Halle, for his researches on chronic renal tuberculosis; a mention to Henri Vignes, for his notes and researches on menstruation; the Baron Larrey prize is not awarded; the Bellion prizè to Henri Gougerot, for his memoir on the treatment of syphilis in practice; a very honourable mention to Emile and Camille Guillot, for their work entitled "The Healthy House"; the Mège and Argut prizes are not awarded; the Chaussier prize is not awarded, but an encouragement (500 francs) is given to Raoul Benon, for his book on posttraumatic psychic and nervous troubles; the Dusgate prize is not awarded, but Arcangelo Creazzo receives a mention for his work on real and apparent death.

Physiology.-The Montyon prize to André Thomas, for his work on the brain; the Philipeaux prize to Henri Stassano, for the whole of his work in physiology; the Lallemand prize between Jules Glover (Iooo francs), for his work on the physiology of the voice applied to art and industry, and Pierre Achalme (80o francs), for his book on electrotonics and biology; no memoirs have been received dealing with the subject proposed for the Pourat prize, and the prize is postponed to I917; the Fanny Emden prize to Jean Chatanay.

Statistics.-The Montyon prize (1000 francs) to Fernand de Montessus de Ballore, for his seismological work.

History of Sciences.-The Binoux prize between Albert Anthiaume, for his work on the history of nautical science, F. Marguet, and George Sarton.

General Prizes.-Berthelot medals to Gabriel Bertrand, M. Viguier, and Paul Pascal; the Becquerel prize between M. Arnaud (2000 francs), Jean Merlin (7.50 francs), and M. Rabioulle (750 francs); the Gegner prize (3800 francs) to G. Cesaro, for his work in descriptive crystallography; the Lannelongue fund, the interest is divided between Mme. Cusco and Mme. Rück; the Gustave Roux prize to Lucien Berland, the prize reserved from roI4 to Georges Lery; the Tremont prize to Charles Frémont; the Wilde prize to Commandant Batailler, for his work in experimental mechanics relating to ballistics; the Lonchampt prize to Fernand Jadin and Albert Astruc, for their work on the presence and estimation of arsenic and manganese in the vegetable kingdom; the Saintour prize to $\mathrm{A}$. Blonde1. for his work on the theory of tides: the Henri de Parville prize between Jean Escard (I000 francs), for his books dealing with scientific and technical questions, Gustave Loisel (rooo francs), and Albert Buisson (500 francs): no memoir dealing with the subject proposed for the Vaillant prize was received, and the prize is postponed to Inig: the Grand prize of the Physical Scienres to Henrv Hubert, for his study of the geolory of French Western Africa; the Le Conte prize to Sir Almroth Wright, for his researches in antityphoid vaccination; the Petit d'Ormov and Laplace and Rivot prizes are not awarded.

\section{WIRELESS COMMUNICATION.}

SOME notes on the present state of wireless telegraphy were communicated by Dr. M. I. Pupin in the course of a lecture which he delivered before the National Academy of Science in New York, on "Aerial Transmission Problems." None of the points raised by Dr. Pupin were entirely new, as they have been frequently discussed in both continents without being appreciably helped towards solution. But the manner in which they were presented and illustrated assisted towards a better understanding of the formidable character of the obstacles in the way of extending the distance of wireless communication. These obstacles are due mainly to the interference produced by electrical waves, which are passing through the terrestrial atmosphere continuously, and it is not until we attempt to magnify the minute signais coming from a distant transmitting station that we are really aware of their presence. An engineer who took part in the recent long-distance wireless telephony trials and listened for the famous telephone message from Arlington, reports that at times "it was drowned completely in a roar of musketry," due, of course, to the action of the electrical waves produced by the incessant electrical discharges in the atmosphere. All attempts up to the present which the "practical" wireless engineer has made in the direction of overcoming these disturbances have consisted in increasing the power applied at the transmitting station so as to make the incoming signals at the receiving station stronger than the signals made by the "static." Ordinary electrical tuning is not sufficient for the purpose, because every system which is highly selective through ordinary tuning is also highly sonorous every tap of the static will cause it to vibrate, and it will vibrate in the same way as when it is under the action of the signalling waves. The method advocated by Dr. Pupin involves the use of a sectional wave conductor between the antenna and the receiving apparatus, which will not transmit electrical waves of a frequency higher than a given range of frequencies. By this means, he states, "the station becomes an ear, which is quite sensitive for frequencies which are in the vicinity of the signalling frequency, which is deaf to frequencies which are considerably beyond this range, as most static disturbances are." "Similarly," he adds, " a sectional wave conductor can be constructed which is quite responsive to frequencies in the vicinity of the signalling frequency, but absorb almost completely everything below this range.'

Dr. Pupin corrects the popular misconception that wireless telegraphy formed its first roots in German soil, whereas in reality it is a particular case of the oscillatory motion of electricity discovered by Joseph Henry, and the laws of which were formulated by Kelvin. It is true that Hertz employed these oscillations more skilfully than anybody else did prior to his time, and thereby succeeded in improving experimentally the complete validity of the physical foundation of the electromagnetic theory which was conceived and formulated by Clerk Maxwell, and paved the way for Mr. Marconi. Dr. Pupin claims that "Marconi discovered wireless telegraphy," but he altogether ignores the achievements of Branly, of Lodge, of Popoff, and others. It cannot be said of Mr. Marconi that he discovered the principles or invented the primary appliances upon which the transmission of electromagnetic waves are based. $\mathrm{He}$ accomplished his result by combining, in the utilisation of linown principles, features which had been disclosed by others. which he improved and co-ordinated, with additional features of his own invention.

Mr. E. H. Colpitts, the research engineer of the Western Electric Company of America, under whose direction the apparatus was developed and the experiments conducted which resulted a few weeks ago in the wireless transmission of speech between Arlington, U.S.A., and Honolulu, on one hand, and Arlington and Paris on the other, discusses in the Scientific American the significance of the recent achievement in long-distance wireless telephony. The technical details of the system have already been described, so far as they are available, and chief interest in Mr. Colpitts's article lies in his views regarding the future of wireless telephony. He does not consider that it will displace line telephony, and even if it is physically possible and can be usefully employed, it must fail to be commercially practicable. Atmospheric disturbances were found to be a great drawback, while another difficulty 